\title{
IJAB KABUL DENGAN LAFAL SELAIN INKAH DAN TAZWIJ MENURUT IBNU TAIMIYAH (Studi Kitab Majmu' Fatawa Jilid 32)
}

\author{
Siti Solekhah \\ Sekolah Tinggi Ilmu Syariah (STIS) Hidayatullah Balikpapan \\ fathelhaq@gmail.com \\ Indah Mahrikatus Syahidah \\ Sekolah Tinggi Ilmu Syariah (STIS) Hidayatullah Balikpapan \\ Indah.mahrika@gmail.com
}

\begin{abstract}
Abstrak
Penelitian ini dilatarbelakangi oleh adanya perbedaan pendapat di kalangan ulama tentang ijab kabul, apakah harus memakai lafal inkāh dan tazwij atau boleh dengan selain dari keduanya. Ibnu Taimiyah yang bermazhab Hambali berpendapat bahwa bolehnya mengucapkan ijab kabul dengan lafal selain inkāh dan tazwïj apabila lafal yang diucapkan dihubungkan dengan lafal yang jelas sehingga dapat dipahami oleh para saksi nikah. Sedangkan menurut pendapat Imam Syafi'i dan Hambali tidak ada akad nikah dengan lafal selain inkāh dan tazwīj, melainkan menggunakan kedua lafal tersebut atau sighah turunan dari inkāh dan tazwīj, mereka berpendapat bahwa akad nikah dengan lafal selain inkāh dan tazwijj nikahnya tidak sah. Penelitian ini menggunakan teknis analisis isi (content analisis) dan teknik dokumentasi (documentation research) yaitu dengan mengumpulkan literatur yang relevan dengan tema skripsi ini dan menghimpun beberapa pendapat ulama mengenai ijab kabul dengan lafal selain inkāh dan tazwīj.
\end{abstract}

\section{Kata Kunci: Ijab kabul, lafal, Inkāh dan Tazwīj.}

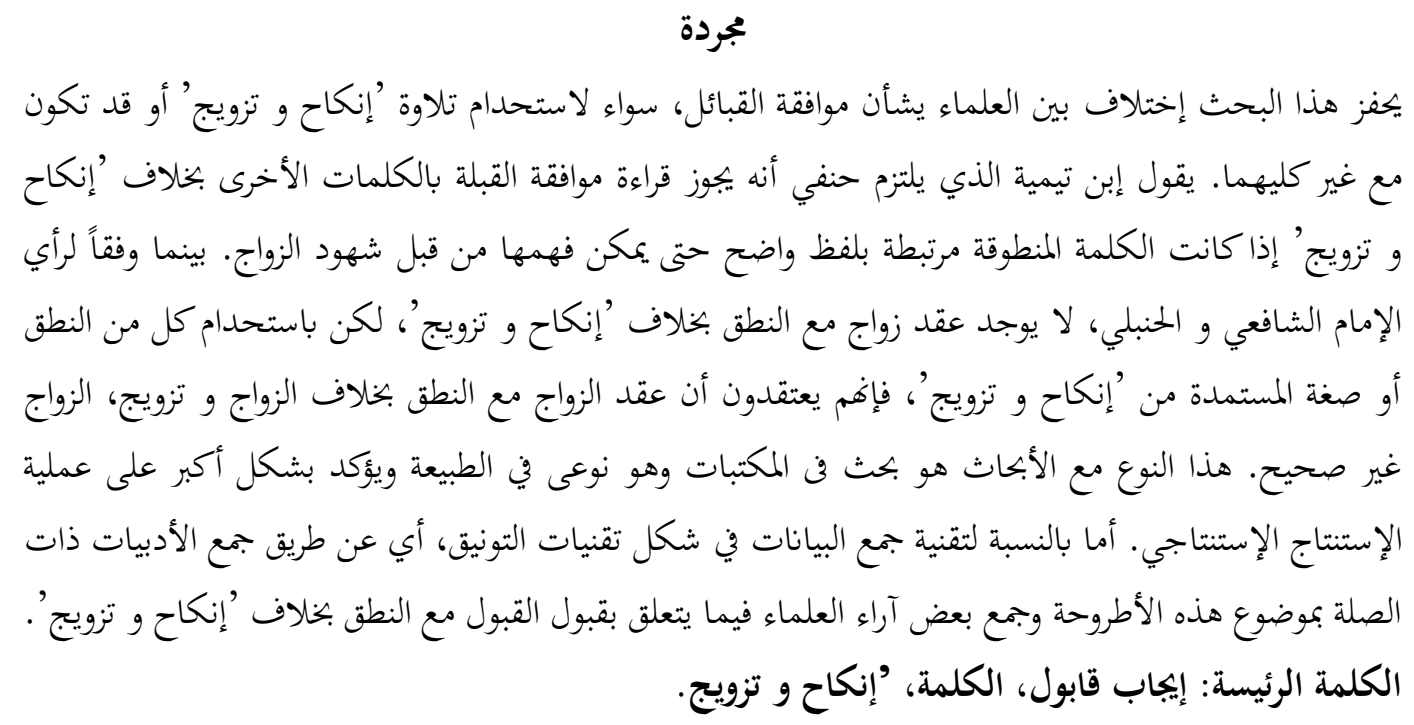

\section{A. Pendahuluan}

Hakikat pernikahan terdapat pada hadirnya keridaan dari kedua belah pihak dan keduanya mempunyai kemauan untuk menjalani suatu hubungan. Kesepakatan 
juga menjadi tolak ukur khusus bagi dua insan yang akan menjalankan pernikahan. Dimulai dari sebuah kata akad nikah, yang mana akad nikah merupakan sebuah perjanjian pernikahan antara pasangan suami istri dan kesepakatan yang telah disepakati dengan serius, sebagaimana firman Allah 形毖 dalam QS. An-Nisa': 21,

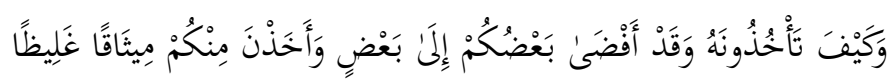

Akad nikah juga mengharuskan sepasang suami istri memenuhi janji yang telah disepakati dari akad yang diucapkan tersebut, yaitu dengan mempertahankan keluarganya secara baik dan melepaskannya secara ihsan,1

Bukti dari bersatunya dua insan yang berbeda adalah dengan melafalkan ijab kabul dalam bentuk ucapan adalah dengan lafal yang diucapkan secara jelas dan dapat dipahami oleh banyak orang, seperti seorang wali berkata "saya nikahkan fulan dengan fulanah" kemudian mempelai pria menjawab "saya terima".

Redaksi akad yaitu ijab dan kabul merupakan akad nikah yang dapat dilakukan dengan kata-kata yang mengandung pengertian akad serta dapat dipahami oleh kedua belah pihak, selama kata yang dipilih adalah kata-kata yang tidak keluar dari maksud akad. ${ }^{2}$ Para ulama berbeda pendapat tentang akad nikah dengan menggunakan lafal inkāh dan tazwīj, apakah ijab tersebut dianggap sah bila menggunakan selain kedua kata itu, seperti kata yang mengandung arti kepemilikan atau sebagainya.

Mazhab Hanafi, Abu Ubaid Abu Tsaur dan Abu Dawud mengemukakan bahwa ijab kabul menggunakan selain lafal inkāh dan tazwīj itu dibolehkan, dengan alasan, ijab adalah akad yang bisa diukur dengan niat, sehingga kata tertentu dalam ijab kabul tidak menjadi sebuah masalah dalam artian kata-kata yang dipilih adalah kata yang sesuai dengan pengertian yang telah ditetapkan oleh syariah. ${ }^{3}$

Madzhab Syafi'i dan Hambali berpendapat bahwa akad tidak sah kecuali dengan shigoh yang berasal dari turunan lafal inkāh dan tazwīj. ${ }^{4}$ Demikian bahwa akadnya tidak sah dengan menggunakan lafal hibah dan tamlīk atau lafal-lafal semacamnya. Sedangkan Ibnu Taimiyah berpendapat dalam kitabnya Majmū' Fatāwa, bahwa bolehnya melafalkan ijab kabul dengan selain inkāh dan tazwīj. Perkataan ibnu Taimiyah sebagai berikut:

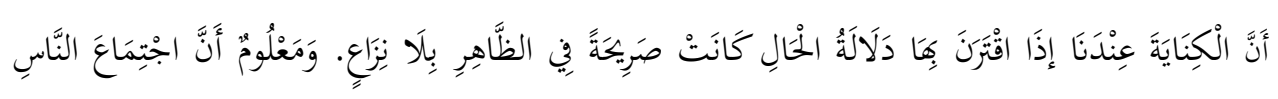

${ }^{1}$ Muhammad Nasib ar-Rifa', Taysiru al-Aliyyul Qadir Li Ikhtisari Tafsir Ibnu Katsir, 334.

2 Sayyid Sabiq, Fiqhus Sunnah, Trans, Asep Sobari et al, (Jakarta Timur: al-I'tishom, 2010), 189.

3 Ibid.190.

4 Abdurrahman al-Juzairi, al-Fiqh 'Ala al-Madzahib al-Arba'ah jilid 5, Trans, Faisal Saleh, (Jakarta: Pustaka al-Kautsar, 2015), 51. 


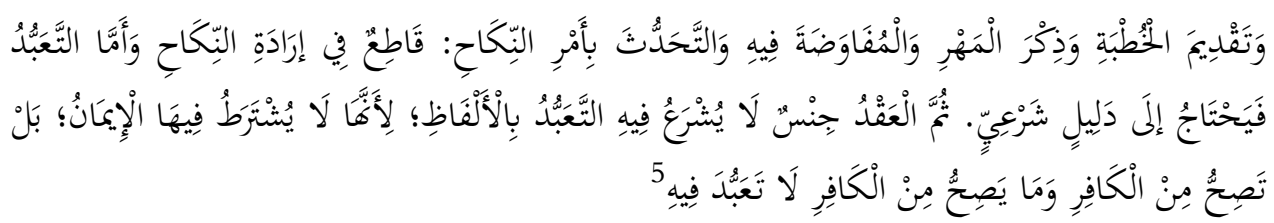

"Apabila lafal kinayah (selain inkāh dan tazwij) terhubung dengan lafal-lafal khusus, itu menunjukkan keadaan yang jelas, tanpa ada perselisihan. Dan telah maklum apabila ada sebuah perkumpulan orang yang mendahulukan khotbah, menyebut mahar, dan terdapat pembicaraan-pembicaraan nikah, maka itu merupakan penetapan pernikahan. Adapun peribadahan itu membutuhkan dalil syar'i, lalu akad sendiri merupakan salah satu jenis peribadahan yang tidak disyariatkan penetapan lafalnya. Bahkan lafal akad apapun menjadi sah bagi orang kafir, dan apa-apa yang menjadikan sah pada orang kafir bukan sebuah peribadahan di dalamnya."

Pemaparan di atas merupakan gambaran pendapat para ulama dalam hal bolehnya menggunakan lafal selain inkāh dan tazwïj dalam pernikahan.

\section{B. Metode Penelitian}

Penelitian ini merupakan penelitian pustaka (libraly research) yaitu sebuah penelitian yang di lakukan dengan berbagai penelitian pustaka baik itu merujuk dari buku-buku, jurnal, makalah, majalah, atau juga berita yang masih ada hubungan dengan judul yang dibahas. Untuk mendapatkan data-data yang lebih akurat dengan sumber-sumber lain yang masih berkaitan.

Penelitian ini bersifat studi literatur (literature study) yaitu seorang peneliti melakukan berbagai tahapan penelitian seperti mempelajari, menelaah, mengkaji lebih dalam buku-buku yang didapat lalu kemudian dengan metode deskriptif analitik akan diuraikan pendapat dan istinbātt hukum Ibnu Taimiyah mengenai ijab kabul dengan lafal selain inkāh dan tazwijj, juga melakukan analisis pemikiran dalam permasalahan tersebut.

Data primer dalam penelitian ini adalah Majmu' Fatawa Jilid 32 sedangkan data sekunder adalah kitab Ibnu taimiyah lainnya yang relevan dengan tema penelitian ini, serta bahan-bahan pustaka baik buku maupun jurnal ilmiah.

\section{Pembahasan}

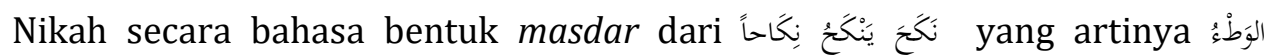

5 Taqiyuddin Abu Abbas Ahmad bin Abdul halim bin Taimiyah al-Huranii, Majmū' Fatāwa Juz 32, (al-Madinah al-Munawwarah: Mujamma' al-Malik Fahdin Lithabaathi al-Mushafi asy-Syarif, 1995),15. 
(senggama), ${ }^{6}$ yaitu menggabungkan dan menyatukan serta saling memasuki. Kata nikah juga bermakna العقد, maksudnya sebuah akad, atau bisa juga bermakna ikatan atau kesepakatan. ${ }^{7}$

Secara syar'i nikah merupakan akad yang mengandung penghalalan antara suami dan istri untuk melakukan wathi' (persetubuhan) dengan tata cara yang disyariatkan, serta penggunaan ijab kabul adalah dari kata inkāh dan tazwïj, atau kata turunan dari keduanya. ${ }^{8}$ Di antara dalil al-Qur'an adalah dalam Q.S an-Nisa': 3, yang berbunyi;

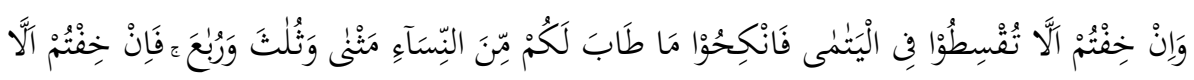

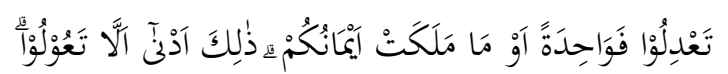

Artinya: Dan jika kamu khawatir tidak akan mampu berlaku adil terhadap (hak-hak) perempuan yatim (bilamana kamu menikahinya), maka nikahilah perempuan (lain) yang kamu senangi: dua, tiga atau empat. Tetapi jika kamu khawatir tidak akan mampu berlaku adil, maka (nikahilah) seorang saja, atau hamba sahaya perempuan yang kamu miliki. Yang demikian itu lebih dekat agar kamu tidak berbuat zalim.

Dalil ini menjadi kesimpulan bahwa ayat ini bersifat perintah yang berindikasi wajib, minimal hukumnya sunnah. ${ }^{9}$ Maka ayat ini merupakan sebuah anjuran untuk melaksanakan pernikahan. Dengan siapa seseorang tersebut akan menikah itu adalah sebuah pilihan, dengan wanita yang memberikan kesenangan

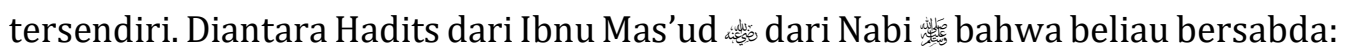

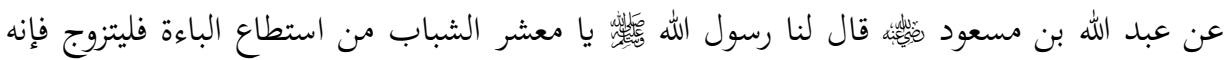

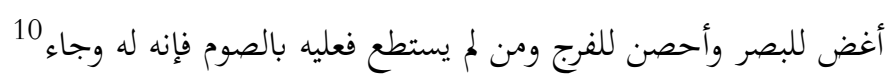

"Wahai sekalian pemuda, siapa di antara kalian telah mempunyai kemampuan, maka hendaklah ia menikah, karena menikah itu dapat menundukkan pandangan, dan juga lebih bisa menjaga kemaluan. Namun, siapa yang belum mampu, hendaklah ia berpuasa, sebab hal itu dapat meredakan nafsunya".

\section{Hukum Nikah}

Nikah merupakan perkara yang disyariatkan. Maka hukum menikah berbeda

6 Achmad Warson Munawwir, Kamus al-Munawwir Arab-Indonesia, (Jakarta: Pustaka Progressif, 1997), 1461.

${ }^{7}$ Ahmad Sarwat, Seri Fikih Kehidupan Jilid 8, (Jakarta: Rumah Fiqih Publishing), 27.

8 Shalih bin Abdul Aziz Alu asy-Syaikh, al-Fiqh al-Muyassar, Trans, Izzudin Karimi, (Jakarta: Darul Haq, 2017), 463.

9 Ibnu Hajar al-Atsqalani, Fathul Bāri Syarah Shahih al-Bukhari Jilid 25, Trans, Amiruddin, (Jakarta: Pustaka Azzam, 2008), 6.

10 Abu Abdillah Muhammad bin Ismail bin Ibrahim Al-Bukhari, Shahih Bukhari Jilid 5, (Surabaya: Maktabah wa Mudhba'ah Thaha, 1981), 117. 
antara yang satu dengan yang lain:

Pertama, wajib jika seseorang mengkhawatirkan dirinya akan terjerumus ke dalam perkara zina, sementara dia mampu memikul tanggung jawab pernikahan dan nafkahnya. Kedua, sunnah bila seseorang memiliki dorongan syahwat kepada lawan jenisnya, serta telah mampu bertanggung jawab. Akan tetapi dia tidak mengkhawatirkan dirinya terjerumus ke dalam perbuatan zina, berdasarkan keumuman ayat-ayat dan hadits-hadits yang memerintahkan agar menikah. Ketiga, makruh bila seseorang tidak menginginkan untuk menikah, seperti seseorang yang impoten, sudah lanjut usia, atau tidak memiliki dorongan syahwat sama sekali. Orang yang impoten adalah seseorang yang tidak memiliki kemampuan untuk menggauli wanita, atau tidak memiliki syahwat pada wanita. ${ }^{11}$ Keempat, Haram jika seseorang tidak mamou untuk memenuhi kewajiban nafkan lahir maupun bathin kepada calon istrinya, sedangkan nafsu yang ia miliki tidak memdesak. Kelima, Mubah jika seserang tidak terdesak oleh alasan yang mewajibkannya segera menikah atau karena alasan yang mengharamkannya yntuk menikah. ${ }^{12}$

\section{Hikmah Nikah}

1. Menjaga kehormatan diri (kemaluan). Ketika Allah menciptakan manusia dengan kesempurnaannya, salah satunya yaitu insting seks dalam tabiatnya, maka Allah jadikan menikah adalah sarana untuk memenuhi kecenderungan ini.

2. Menghadirkan ketenangan dan kesenangan antara laki-laki dan perempuan untuk merealisasikan kedamaian dan ketenteraman.

3. Mewujudkan keturunan yang beriman yang menjadi penerus estafet perjuangan dakwah, serta mereka yang memohon ampunan kepada Allah untuk orang-orang yang beriman.

4. Menjaga nasab, menguatkan jalinan kekerabatan antara sebagian yang satu dengan yang lain.

5. Menjaga akhlaq manusia agar tidak terjerumus ke dalam perbuatan zina yang hina dan berbagai perbuatan yang di haramkan. ${ }^{13}$

\section{Rukun-rukun Nikah}

Rukun-rukun yang harus terlaksana dalam sebuah pernikahan dan terwujudnya sebuah pernikahan sebagai berikut: pertama: Dua pihak pelaku akad, yaitu mempelai pria dan wanita yang terbebas dari penghalang-penghalangnya. Kedua : Ijab, kalimat yang diucapkan oleh wali atau yang mewakili dengan kata,

\footnotetext{
11 Shalih bin Abdul Aziz Alu asy-Syaikh, al-Fiqh al-Muyassar, 465.

12 Wahyu Wibisana, "Pernikahan dalam Islam", Ittihad 14, no. 2, (n.p, 2016), 189.

13 Ibid, 470.
} 
"menikahkan atau mengawinkan". Ketiga :Kabul, kalimat yang diucapkan oleh mempelai pria atau yang mewakili dengan kata, "Saya menerima atau Saya rela dengan pernikahan ini".

\section{Syarat-syarat Nikah}

1. Penentuan secara jelas di setiap pasangan dari calon suami dan istri. Pernikahan akan di anggap tidak sah, apabila tidak di tentukan secara jelas pasangannya, misalnya wali berkata: "aku nikahkan kamu dengan anak perempuanku”, padahal dia mempunyai anak perempuan lebih dari satu. ${ }^{14}$

2. Kerelaan dari setiap pengantin terhadap pasangannya. Pernikahan akan menjadi tidak sah apabila ada unsur paksaan dari salah satu pihak. sebagaimana hadits Abu Hurairah dari Rasulullah 能 bersabda: "Janda tidak dinikahkan hingga diajak musyawarah, dan gadis perawan tidak dinikahkan hingga dimintai izin.” Mereka berkata, “Wahai Rasulullah 龂, bagaimana izinnya?” Beliau bersabda, “Dia diam" ${ }^{15}$

3. Wali dalam pernikahan menjadi sangat penting dalam pelaksanaan akad nikah. Fuqaha' yang menjadikan wali sebagai persyaratan sahnya pernikahan juga beralasan dengan hadits Ibnu Abbas berikut ini:

$$
\text { عن أبي موسى قال قال رسول الله صلى الله عليه وسلم :لا نكاح إلا بولي (رواه البخاري و أبو }
$$

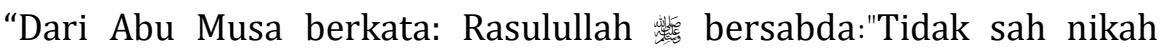
kecuali dengan adanya wali". (HR. Bukhari dan Abu Dawud). ${ }^{16}$

4. Saksi, kesaksian merupakan syarat sah akad nikah, maka kemudian kesaksian itu harus ada dalam sebuah pernikahan. Jumlah minimal saksi nikah adalah dua orang , akan tetapi kesaksian bisa di anggap sah bila terdiri dari satu orang dan dua orang perempuan. ${ }^{17}$

\section{Akad Nikah}

Maksud kata "akad" adalah kesepakatan atau perjanjian antara dua belah pihak yang menuntut masing-masing mengucapkan isi kesepakatannya. seperti halnya akad jual beli dan akad nikah. ${ }^{18}$ Adapun pihak yang berperan dalam akad adalah laki-laki dan perempuan. Sedangkan nikah artinya adalah perkawinan atau perjodohan, jadi akad nikah adalah pernyataan kesepakatan (perjanjian)

\footnotetext{
14 Shalih bin Abdul Aziz Alu asy-Syaikh, al-Fiqh al-Muyassar, 470.

15 Ibnu Hajar al-Atsqalani, Fathul Bāri Syarah Șahih al-Bukhārī, Hadits no. 5136, 309.

${ }^{16}$ Abu Dawud Sulaiman bin al-Asy'ats as-Sajastani al-Azdii, Sunan Abu Dawud Jilid 2, (n.p.: Darul al-Fikri, n.d.), 229.

${ }^{17}$ Abdurrahman Al-Jazairi, Fiqh 'Ala Madzahib al-Arba'ah Jilid 5, 36.

18 Umar Sulaiman Al-Asyrar, Pernikahan Syar'I, 1st ed, (Solo: Tiga Serangkai, 2015), 13.
} 
perkawinan. ${ }^{19}$

Akad nikah dibangun atas dasar keinginan dan kerelaan dari kedua belah pihak. Lafal yang menjadikan akad tersebut sempurna dan menunjukkan kerelaan dari kedua belah pihak atas isi akad itu disebut ijab dan kabul. Ijab adalah lafal yang diucapkan pihak pertama yang menunjukkan kemauan untuk membentuk sebuah hubungan suami istri.20 Kabul adalah lafal yang diucapkan pihak kedua yang mengungkapkan kerelaan dan persetujuannya terhadap isi akad, ${ }^{21}$ dan kabul merupakan penyebab sahnya sebuah pernikahan, keduanya wajib dinyatakan oleh pihak yang sah mengadakan akad nikah.

a) Syarat-syarat Akad Nikah

1) Sighah ijab kabul disyaratkan menggunakan lafal tertentu.

Seperti, jika wali berkata, "Zawwajtukahā ibnati (aku nikahkan kamu dengan putriku)", kemudian pengantin berkata, "Qabiltu hadzat tazwijj (aku terima nikah ini)". Begitupun jika wali mengatakan, "ankahtuka ibnati (aku nikahkan kamu dengan putriku)", lalu mempelai menjawab, “Qabiltu (aku terima)", maka akad nikah yang di laksanakan telah sah. ${ }^{22}$

2) Kesesuaian antara lafal ijab dan kabul. Apabila lafal ijab yang diucapkan berbeda dengan lafal kabul, maka akad tersebut batal.

3) Lafal ijab dan kabul harus di lakukan secara beruntun.

Pendapat Imam Syafi'i adalah Jika terdapat jeda yang cukup singkat atau pendek maka tidak masalah. ${ }^{23}$ Menurut jumhur ulama: Hanafiyah, Malikiyah, dan Hanabilah tidak mensyaratkan kabul diucapkan segera, karena keterlambatan pengucapan kabul tidak merusak akad, selama ucapan kabul diucapkan dalam satu majlis. ${ }^{24}$

4) Sighah lafal disyaratkan menunjukkan sifat dawam (selamanya) dan berlaku segera.

Apabila sighah ijab dihubungkan dengan masa mendatang atau menunjukkan pembatasan waktu, maka ijabnya tidak sah. Contoh: seperti ungkapan seorang, "aku akan menikahimu bila tiba bulan November", lalu dijawab "aku terima". Atau jika berkata, "aku akan menikahimu jika saudaraku

19 Hadi Mufaat Ahmad, Fikih Munakahat; Hukum Perkawinan Islam Dan Beberapa Permasalahannya, (Semarang: Duta Grafika, 1992), 101.

20 Sayyid Sabiq, Fikih Sunnah Jilid 6, 53.

21 Muhammad Nashiruddin Al-Albani et al, Shahih Fikih as-Sunnah Jilid 4, trans, Abu Ihsan alAtsari, (Jakarta: Pustaka at-Tazkia, 2008), 179.

22 Hasan Ayyub, Fikih Keluarga, Trans, Abdul Ghaffar, Cet 5, (Jakarta Timur: Pustaka al-Kautsar, 2006), 82.

23 Al-Asyrar, Umar Sulaiman, Pernikahan Syar'i, 89.

24 Muhammad Nashiruddin al-Albani et al, Shahih Fikih as-Sunnah Jilid 4, 181. 
datang", lalu di jawab "aku terima", maka kabul seperti itu tidak sah. Pernikahan tersebut dianggap batil, karena lafal "menggantungkan" atau penambahan seperti itu bertentangan dengan kewajiban yang ada pada akad nikah. ${ }^{25}$

5) Orang yang mengemukakan ijab tidak menarik kembali ijabnya sebelum pihak lain mengucapkan kabul.

An-Nawawi berkata, “Jika lafal ijab diucapkan oleh salah satu pihak, maka si pengucap tetap menjaga pernyataan itu, sampai lafal kabul terucap. Jika pengucap ijab mencabut kembali lafal ijab yang ia ucapkan, maka akad tersebut batal". ${ }^{26}$

Adapun Syarat Ijab Kabul adalah: “Kedua mempelai sudah tamyīz, ijab dan kabul dilaksanakan dalam satu majlis, hendaknya ucapan kabul tidak menyalahi ijab, hendaknya para saksi benar-benar menyaksikan ucapan ijab kabul tersebut".

b) Macam-macam Lafal Akad Nikah

1) Lafal sharih (jelas secara verbal)

Lafal sharih adalah kata yang jelas baik dalam hal kalimat atau makna. Maka dalam ijab kabul dapat menggunakan bentuk mādhi, yaitu dengan lafal inkāh atau tazwijj, atau lafal yang masih satu turunan dari lafal nikah dan zawaj. ${ }^{27}$ Misalnya: "Ankahtuka" atau "Zawwajtuka". Contoh, pihak pertama berkata, "Zawwajtukahā Ibnati (Aku telah menikahkanmu dengan anakku)”, lalu pihak kedua menjawab, “Qabiltu (Aku terima)”.

2) Lafal kinayah (Sindiran)

Definisi kinayah adalah:

$$
\text { لفظ يطلق ويرأد به لازم معناه مع جواز إرادة المعنى الأصلي } 28
$$

"Lafal yang disampaikan dan dimaksud yaitu kelaziman dari makna tersebut, boleh juga menunjukkan pada makna asli.

Bahwasanya lafal kinayah adalah lafal yang biasa digunakan untuk mengungkapkan sesuatu agar tidak langsung pada makna yang dimaksud, sekalipun ungkapan tersebut dapat diartikan dengan makna yang

\footnotetext{
2005), 66 .

25 Abdul Majid Mahmud Mathlub, Panduan Hukum Keluarga Sakinah, (Solo: Era Intermedia,

26 Umar Sulaiman al-Asyrar, Pernikahan Syar'i, 91.

27 Al-Juzairi, Abdurrahman. Fikih Empat Madzhab. 6th ed. Vol. 5. Jakarta: Pustaka Al-Kautsar, 2012.Jilid 5, 29.

${ }^{28}$ Muhammad 'Ali as-Saraji, al-Lubāb Fì Qawā'id al-Lughah Jilid 1, (Damaskus: Dar al-Fikr), 177, Maktabah Syamilah.
} 
sesungguhnya. ${ }^{29}$

Lafal kinayah merupakan lafal yang diperbolehkan dalam pengucapan akad nikah seperti kinayah menggunakan lafal hibah, kepemilikan, atau upah. Bahwa akad nikah dengan lafal kinayah dianggap sah menurut madzhab Hanafi serta tidak ada perbedaan pendapat di dalamnya. ${ }^{30}$ Misalnya: jika seorang wanita mengatakan, "saya menghibahkan diri saya kepada mu" dengan niat menikah, lalu menjawab, "saya terima", maka pernikahan tersebut telah terlaksana. Atau apabila mempelai pria berkata, “Amlaktukahā (Aku kuasakan anak perempuanku kepadamu)" atau A'thaitukahā (Aku berikan anak perempuanku kepadamu)". Maka lafal seperti itu dianggap sah. Seperti jika seseorang berkata, "A'thaitukahā zawjatan (Aku berikan anak perempuanku kepadamu sebagai istri)", lalu pihak kedua menjawab, “Qabiltu (Aku terima).

c) Hukum Ijab Kabul Selain Inkāh dan Tazwïj

Para ulama fiqih sepakat bahwa tidak ada redaksi akad dalam masalah kabul yang mensyaratkan dengan kata tertentu, melainkan boleh menggunakan bentuk kata selama menunjukkan persetujuan dan penerimaan. ${ }^{31}$ Seperti kata. "Aku terima atau aku setuju". Sedangkan dalam masalah ijab para ulama fiqih sepakat bahwa bentuk kata dalam melafalkan ijab menggunakan kata inkāh dan tazwīj. Berbeda dengan ijab yang diucapkan dengan kata selain inkāh dan tazwīj, apakah pernikahannya di anggap sah atau tidak. Maka inilah yang menjadi perbedaan pendapat para ulama fiqih dalam menetapkan.

Pertama, pendapat Imam Syafi'i dan Imam Hanbali, bahwa tidak ada akad nikah menggunakan lafal lain selain inkāh dan tazwīj, melainkan menggunakan lafal keduanya, atau sighah yang berasal dari turunan kata inkāh dan tazwīj. Mereka berpendapat bahwa akad nikah dengan lafal selain inkāh dan tazwijj seperti dengan kata hibah, atau tamlīk, maka nikahnya tidak sah. ${ }^{32}$

Kedua, pendapat Imam Malik tidak sependapat dengan imam-imam lain. Yaitu akadnya sah dengan lafal hibah atau tamlīk, akan tetapi dengan syarat jika disertai dengan penyebutan mahar. Misalnya, jika seorang wali mengatakan, "Aku hibahkan anak perempuan saya kepadamu dengan mahar sekian". Atau jika mempelai pria berkata, "hibahkan anak perempuanmu kepada saya dengan mahar

29 "Pengertian Kinayah dan Macam-Macamnya" Hahuwa, accessed September, 2017, https://hahuwa.blogspot.com/.

${ }^{30}$ Abdurrahman al-Jazairi, Fiqh 'Ala Madzahib al-Arba'ah Jilid 5, 33.

${ }^{31}$ Sayyid Sabiq, Fiqih Sunnah Jilid 2, 189.

32 Abdurrahman al-Jazairi, Fiqh 'Ala Madzahib al-Arba'ah Jilid 5, 41. 
tersebut. 33

Ketiga, Imam Abu Hanifah mengatakan akad menggunakan lafal kinayah, seperti lafal hibah atau tamlīk, maka akad tersebut sah serta tidak ada penghalang baginya, sebab yang penting dalam ijab adalah niatnya, maka semua lafal yang cocok dan bisa dimengerti maknanya secara hukum dianggap sah. ${ }^{34}$

\section{Biografi dan Pemikiran Ibnu Taimiyah Tentang Ijab Kabul dengan Lafal Selain Inkāh dan Tazwīj}

1. Nasab dan Kelahiran

Nama lengkap Ibnu Taimiyah adalah Ahmad bin Abdul Halim bin Abdussalam bin Abdullah bin al-Khadhir bin Muhammad bin al-Khadhir bin Ali bin Abdullah bin Taimiyah an-Namiri al-Harrani ad-Dimasyqi Abu al-Abbas Taqiyyuddin Syaikhul Islam. ${ }^{35}$ Keluarga Ibnu Taimiyah di kenal baik dengan sebutan Bani Taimiyah, penamaan ini disebabkan karena ibu dari salah satu kakek mereka yang bernama Taimiyah adalah seorang aktivis dakwah yang cukup terkenal, maka keluarga ini dikenal dengan nama tersebut. ${ }^{36}$

Penamaan ini (Taimiyah) bermula dari kejadian di saat kakek Ibnu Taimiyah yang bernama Muhammad bin Khiwdhir pergi berhaji sementara istrinya sedang hamil. Ketika melewati desa kecil bernama Taimi', dia melihat gadis kecil keluar dari tenda. Maka setelah kembali ke Harran, ternyata dia mendapati istrinya telah melahirkan anak perempuan. Ketika mereka memperlihatkan anaknya kepada kakek Ibnu Taimiyah, dia mengatakan, "Hai Taimiyah, hai Taimiyah". Maka jadilah sebutan itu menjadi maknanya. Ibnu Nashiruddin ad-Dimasyqi menyebutkan dalam atTibyan, dia mengatakan bahwa ibu dari kakek Ibnu Taimiyah yaitu Muhammad bin Khidhir adalah pemberi nasehat yang biasa dipanggil dengan Taimiyah, lalu dia dinisbatkan kepadanya. ${ }^{37}$

Ahmad bin Abdul Halim bin Taimiyah atau lebih dikenal dengan sebutan Ibnu Taimiyah lahir pada 10 Rabiul Awal 661 H di Harran sebelah timur laut Negara Turki. Harran adalah sebuah kampung tempat asal Nabi Ibrahim cuaca di Harran yang cukup memberikan pengaruh pada Ibnu Taimiyah, menjadikannya sosok yang berperilaku bersih, santun dan Istiqamah, serta tumbuh dengan didikan keluarga

33 Ibid, 51.

34 Slamet Abidin, Fikih Munakahat, 1st ed, (Bandung: CV Pustaka Setia, 1999), 74.

35 Ahmad Farid, Biografi 60 Ulama Ahlus Sunnah, Trans, Ahmad Syaikhu, Cet 4. (Jakarta: Darul Haq, 2016), 874.

${ }^{36}$ Hasan al-Jamal, Biografi 10 Imam Besar, Trans, Khaled Muslih, Cet 1, Jakata: Pustaka AlKautsar, 2005), 203.

37 Ahmad Farid, Biografi 60 Ulama Ahlus Sunnah, 875. 
yang baik. Ibnu Taimiyah dibesarkan di kota ini hingga berumur 16 tahun. Setelah beberapa tahun tinggal di Harran, Ibnu Taimiyah pindah bersama ayahnya juga bersama dua saudaranya ke Damaskus ", pada tahun 677 H, yang bertepatan dengan kedatangan serangan Tartar ke Syam. Damaskus adalah sebuah Negeri ilmu, Ibnu Jubair berkata, "Barangsiapa yang menginginkan sebuah keberuntungan, maka pergilah ke Negeri ini dengan niat menuntut ilmu, niscaya dia akan mendapatkan banyak hal-hal yang dibutuhkannya, yang pertama adalah tidaklah risau dengan urusan biaya hidup. ${ }^{38}$

Ibu Ibnu Taimiyah, beliau hidup hingga menyaksikan kejayaan anaknya, bahkan ikut andil dalam jihad anaknya Ibnu Taimiyah. Ketika dalam penjara Ibnu Taimiyah selalu mengirim surat untuk ibunya yang berisikan ungkapan kasih sayang juga titipan tetesan air mata rindu. Ayah Ibnu Taimiyah bernama Abdul Halim bin Abdussalam Syihabuddin, lahir di Harran 627 H, ayahnya belajar dari ayahnya Abdussalam dan beberapa guru lainnya. Ayah Ibnu Taimiyah mendalami Madzhab Hambali dari ayahnya hingga benar-benar memahaminya, setelah itu ia mengajar dan mengeluarkan fatwa sebagai Imam yang sangat teliti, mempunyai perangai yang sangat terpuji, ia juga sangat dermawan dan ringan tangan. Wafat di Damaskus pada tahun 683 H. ${ }^{39}$

Kakek Ibnu Taimiyah bernama Abdussalam bin Abdullah, dia terbilang seorang fakih dari Madzhab Hambali, seorang Imam, ahli hadits, mufasir yang fakih dan menguasai ilmu-ilmu bahasa, di kenal dengan salah satu seorang Huffah yang tersohor, pengarang buku; "Muntaqa al-Akbar", yang telah di syarh oleh Imam asySyaukani dengan judul "Nailul Authar Syarh Muntaqa al-Akbar". Ia lahir di Harran pada tahun $590 \mathrm{H}$, kemudian hijrah dan tinggal beberapa tahun di Baghdad, lalu kembali lagi ke Harran, dan wafat pada tahun $652 \mathrm{H}$ di Harran. ${ }^{40}$

Sejak kecil, Ibnu Taimiyah telah memulai belajarnya yang dimulai dari mempelajari al-Qur'an dan Hadits kepada ayahnya. Ketika datang serangan Tartar ke negeri Syam, ia dan keluarganya pindah ke Damaskus, sebuah Kota yang menjadi pusat ilmu terbesar pada saat itu. Hari-hari yang dilalui Ibnu Taimiyah ia sibukkan dengan belajar.41 Pada usianya 10 tahun ia mampu menghafal serta memahami beberapa kitab terkemuka, seperti; kitab Musnad Ahmad (himpunan hadits-hadits

38 Said Abdul Azhim, Ibnu Taimiyah Pembaruan Salafi dan Dakwah Reformasi, Trans, Faisal Saleh dan Khoerul Amru Harahap, Cet , (Jakarta: Pustaka Al-Kautsar, 2005), 15-17.

${ }^{39}$ Hasan al-Jamal, Biografi 10 Imam Besar, 204.

40 Ibid, 205.

41 Muhammad Syaikhon, "Pemikiran Hukum Islam Ibnu Taimiyah" Ittihad 7, no. 2 (Desember 2015), 335 . 
yang diriwayatkan oleh Imam Ahmad bin Hanbal), Al-Kutub as-Sittah (enam kitab hadits), Mu'jam at-Tabrani (kamus yang dikarang oleh a-Tabrani), beliau juga belajar ilmu khat, ilmu hisab, hafalan qur'an, dan mendalami bahasa Arab dari Ibnu Abdul Qawi. Kemudian ia tertarik untuk mempelajari ilmu kalam dan filsafah, dan menjadi ahli dalam kedua bidang tersebut. Ibnu Taimiyah mampu menyelesaikan seluruh pendidikannya pada usia 20 tahun. Setahun kemudian ia menggantikan kedudukan ayahnya yang telah wafat sebagai ulama besar hukum Mazhab Hambali. Beliau juga di kenal sebagai ahli hadits, ahli kalam, fiqih, mufasir (ahli tafsir), filsuf dan sufi. Keluasan ilmu keislaman yang beliau miliki sehingga pantas mendapat gelar Syaikhul Islam. Pada usia 30 tahun, Ibnu Taimiyah telah menyandang gelar ulama besar pada zamannya sampai sekarang. 42

Ibnu Taimiyah menyandang seorang mufti pada umur menjelang 21 tahun, beliau mengabdikan ilmu yang beliau miliki demi kepentingan agama Islam dan umat. Setelah ayah beliau wafat pada tahun 682 H/1284M, beliau menggantikan kedudukan ayahnya sebagai Direktur Madrasah Dar al-Hadits as-Syukkariyah dan menggantikan kedudukan ayahnya sebagai guru besar hadits dan fiqh Hambali di madrasah tersebut. 43

a) Wafatnya Ibnu Taimiyah

Ibnu Taimiyah wafat pada waktu subuh (menjelang fajar) malam senin, yakni malam 20 Dzulqa'dah 728 H. Beliau berada di dalam penjara Qal'ah selama dua tahun tiga bulan beberapa hari, kemudian beliau wafat. Selama di penjara Ibnu Taimiyah

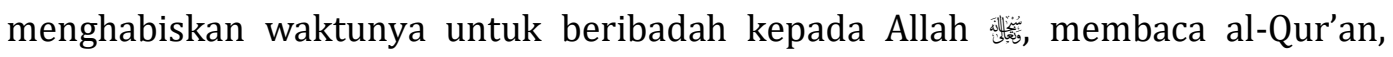
menulis buku dan menulis bantahan-bantahan terhadap kelompok-kelompok yang menyimpang (Al-Ikhna'iyah, ar-Radd 'Ala Ba'dh Qudhat asy-Syafi'iyah). Beliau juga menulis tafsir ayat dan surat al-Qur'an.

b) Guru dan Murid Ibnu Taimiyah

Guru-guru Ibnu Taimiyah diantaranya adalah Zainuddin Abu al-Abbas Ahmad bin Abd ad-Da'im, al-Imam, al-Muhandits, sanad zaman (ilmu sanad), Taqiyuddin Abu Muhammad Isma'il bin Ibrahim bin Abu al-Yusr at-Tanukhi, seorang musnid yang masyhur, Ibnu Taimiyah telah mendapatkan madrasah sejak kecil oleh ayahnya yaitu Syihabuddin Abdul Halim bin Abdussalam at-Taimiyah. ${ }^{44}$

Murid-murid Ibnu Taimiyah diantaranya adalah Ibnu Qayyim al-Jauziyah,

42 Dewan Redaksi Ensiklopedi. Ensiklopedi Islam, 11th ed. Vol. 5, (Jakarta: Ichtiar Baru Van Hoeve, 2003), 169.

43 Qamaruzzaman, Pemikiran Politik Ibnu Taimiyah, STAI Mempawah Kalimantan Barat, ittihad 2, no, 2 (Desember 2019), 114.

${ }^{44}$ Ahmad Farid, Biografi 60 Ulama Ahlus Sunnah, 902. 
Syamsuddin Abu Abdillah Muhammad bin Ahmad bin Abdul Hadi, Imaduddin Abu alFida' Isma'il bin Umar bin Katsir al-Bashri al-Qurasyi ad-Dimasyqi, Ibnu Rajab. ${ }^{45}$

c) Karya-karya Ibnu Taimiyah

1) Karya Ibnu Taimiyah dalam Bidang al-Qur'an dan Ilmu al-Qur'an: Muqaddimah Fì Ushul at-Tafsīr, Qā’idah Fī Tahzīb al-Qur'ān, At-Tibyān Fì Nuzul al-Qur'ān.

2) Karya Ibnu Taimiyah dalam Bidang Hadits dan Ilmu Hadits: As'ilah Fī Mushthalah al-Hadits, Syarh al-Hadits "Nazala al-Qur'ān 'ala Sab'ah Ahruf", Syarh al-Hadits an-Nuzul.

3) Karya Ibnu Taimiyah dalam Bidang Aqidah: Al-Iman al-Kabīr, Mu'jizat alAnbiyā', Risālah Fī Kalāmillah.

4) Karya Ibnu Taimiyah dalam Bidang Fiqih dan Ushul Fiqih: Ushul Fiqih, Risālah Fī al-Ijtihād, Risālah Fì Aqwal ash-Shahabah Wa Hujjiyatihā.

5) Karya Ibnu Taimiyah dalam Bidang Tasawwuf, Etika, dan Sosial: Ash-Shuffiyyah Wa al-Fuqahā', Al-Hasanah Wa as-Sayyi'ah, As-Siyasah asy-Syar'iyyah.

6) Karya Ibnu Taimiyah dalam Bidang Logika dan Filsafah: Naqdhu al-Mantiq, ArRadd 'Ala al-Manthiqiyyah.

d) Metode Istinbāt Ibnu Taimiyah dalam Menetapkan Hukum

Metode pemikiran yang digunakan oleh Ibnu Taimiyah telah diuraikan secara rinci yang dapat dilihat dalam kitab Majmū' Fatāwa (Kumpulan Fatwa-Fatwa). Metode pemikiran Ibnu Taimiyah adalah metode salaf yang bersumber dari al-Qur'an dan as-Sunnah (Hadits). ${ }^{46}$ Adapun metode istinbāt hukum yang dipakai oleh Ibnu Taimiyah dalam menetapkan suatu hukum sebagai berikut:

1) Nash (al-Qur'an dan as-Sunnah)

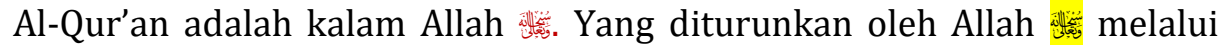
perantara Malaikat Jibril kepada Nabi Muhammad 齔. Teks lafal dalam al-Qur'an menggunakan bahasa Arab agar dapat menjadi renungan, diingat, dan berdasarkan riwayat mutawatir, dengan makna yang benar sebagai hujjah bagi Rasulullah 擎 47

As-Sunnah adalah segala yang datang dari Nabi Muhammad, baik berupa perkataan, perbuatan. Adapun taqrir, juga sifat-sifat dan prilaku atau perjalanan hidup Rasulullah 能 sebelum maupun sesudah diangkat menjadi seorang Nabi.48

45 Ibid, 903.

46 Dewan Redaksi Ensiklopedi Islam, Ensiklopedi Islam Jilid 5, 170.

47 Abdul Wahab Khallaf, Ilmu Ushul Fiqih (Jakarta: Al-Majlis al-'A'la Indonesia Li ad-Dakwah, 1972), 23.

48 Nasrun Haroen, Ushul Fiqih, (Jakarta: Logos Publising, 1996), 38. 


\section{2) Ijma' dan Qiyas}

Ijma' adalah suatu kesepakatan para mujtahid dari kalangan umat nabi Muhammad setelah beliau wafat. Jumhur ulama sepakat akan kelayakan ijma' sebagai salah satu hujjah syar'iyyah yang wajib diamalkan bagi seorang muslim. ${ }^{49}$

Qiyas adalah menyamakan, membandingkan, atau mengukur. Seperti menyamakan antara si A dan si B, lantaran mereka mempunyai tinggi yang sama. Menurut ulama ushul fiqih, Qiyas ialah menetapkan hukum suatu kejadian atau peristiwa yang tidak ada dalam nash dengan cara membandingkan kepada suatu kejadian yang telah ditetapkan hukumnya berdasarkan nash dikarenakan adanya kesamaan illat dari kedua perbandingan tersebut. ${ }^{50}$

e) Sekilas Tentang Majmū' Fatāwa

Kitab Majmū' Fatāwa merupakan kitab dari kumpulan fatwa-fatwa Ibnu Taimiyah yang dengan usaha Syaikh Abdurrahman bin Muhammad bin Qasim beserta putranya Muhammad bin Abdurrahman, mengumpulkan tulisan yang telah dicetak dalam jumlah yang tidak sedikit lalu menambahkan bagian manuskrip yang belum pernah diangkat sebelumnya, kemudian keduanya menerbitkan risalah-risalah yang sudah selesai dihimpun, baik yang sudah dicetak maupun yang masih berbentuk masukrip, dengan judul Majmū' Fatāwa Syaikhul Islam Ahmad bin Taimiyah dalam tiga puluh tujuh jilid. ${ }^{51}$ Adapun bab yang membahas tentang nikah adalah dari bab 3234.

\section{f) Pendapat Ibnu Taimiyah tentang Ijab Kabul dengan lafal Selain Inkāh dan Tazwīj}

Terkait dengan perkara ijab kabul dengan lafal selain inkāh dan tazwïj, Ibnu Taimiyah berpendapat dalam kitab Majmü' Fatāwa jilid 32,

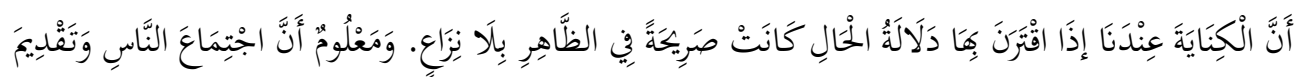

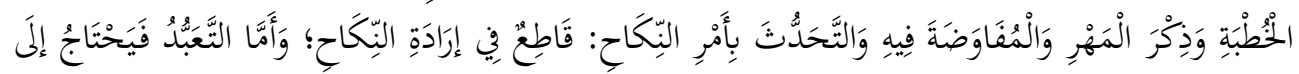

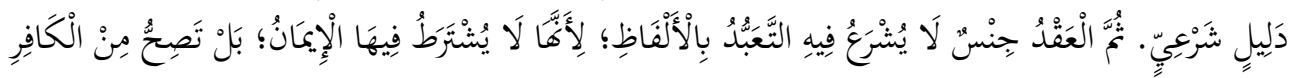

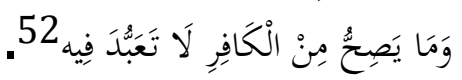

“Apabila lafal kiyasan (selain inkāh dan tazwīj) terhubung dengan lafal-lafal khusus, itu menunjukkan keadaan yang jelas, tanpa ada perselisihan. Dan telah maklum apabila ada sebuah perkumpulan orang yang mendahulukan khutbah,

${ }^{49}$ Saifuddin Abi Hasan Ali bin Muhammad al-Amidi, Al-Ahkam Fi Ushul al-Ahkam, Cet 1, (Beirut: Dar al-Fiqr, 1996), 45.

50 Achmad Yasin, Ilmu Ushul Fiqih (Dasar-Dasar Istinbāt Hukum Islam), Prodi Siyasah Jinayah Jurusan Hukum Islam, Fakultas Syari'ah dan Hukum UIN Sunan Ampel Surabaya, ittihad 7, no 2, Surabaya, 2007, 81.

51 Taqiyuddin Abu Abbas Ahmad bin Abdulhalim bin Taimiyah Al-Huranii, Majmū' Fatāwa Juz 32, (al-Madinah al-Munawwarah: Mujamma' al-Malik Fahdin Lithabaathi al-Mushafi asy-Syarif, 1995), 4. 32,17 .

52 Taqiyuddin Abu Abbas Ahmad bin Abdulhalim bin Taimiyah al-Huranii, Majmū' Fatāwa Juz 
menyebut mahar, dan terdapat pembicaraan-pembicaraan nikah, maka itu merupakan penetapan pernikahan. Adapun peribadahan itu membutuhkan dalil syar'i, lalu akad sendiri merupakan salah satu jenis peribadahan yang tidak disyariatkan penetapan lafalnya. Bahkan lafal akad apapun menjadi sah bagi orang kafir, dan apa-apa yang menjadikan sah pada orang kafir bukan sebuah peribadahan di dalamnya."

Pada dasarnya kiyasan tidak membutuhkan hadirnya niat secara mutlak, akan tetapi jika lafal kiyasan dihubungkan dengan lafal-lafal yang jelas atau dihubungkan dengan suatu hukum dari hukum-hukum akad, maka lafal kiyasan akan menjadi shārih (jelas) dari makna yang dimaksud. Sebagaimana halnya kiyasan dalam bab wakaf, seperti; "Aku telah menshadaqahkan", "Aku telah mengharamkan", dan "Aku telah mengekalkannya". Lalu apabila kiyasan pada lafal akad nikah yang dihubungkan dengan suatu lafal atau suatu hukum, seperti; "Amlaktukaha (Aku telah menguasakanmu kepadanya)", kemudian dijawab, “Qabiltu Hadza Tazwij (aku terima perjodohan ini)”, atau “A'thaitukahā Zaujatan (Aku telah memberikannya kepadamu sebagai istri)”, kemudian dijawab, “Qabiltu (Aku terima)", atau, "Aku kuasakan ia padamu atas apa-apa yang telah Allah perintahkan padanya dari menggaulinya dengan ma'ruf atau memceraikannya dengan ma'ruf', maka lafal tersebut telah menjadikan lafal-lafal akad menjadi shārih (jelas). ${ }^{53}$

g) Metode Istinbāt Ibnu Taimiyah Terhadap Pendapatnya Tentang Ijab Kabul dengan Lafal Selain Inkāh dan Tazwīj

Mengenai metode istinbāt Ibnu Taimiyah adalah berlandaskan pada hukum asal secara nash (al-Qur'an dan as-Sunnah), selama hukum itu belum di mansukh menurut syara'. istinbāṭ ini merupakan hujjah bagi ketidak adaan ittifaq. ${ }^{44}$ Ketika seorang mujtahid dihadapkan suatu masalah, maka jalan pertama adalah dikembalikan pada hukum asal sesuatu berdasarkan nash, jika dalam hukum asal permasalahan tersebut tidak ditemukan, maka permasalahan tersebut ditimbang atau dipecahkan dengan beberapa tahapan yaitu dengan ijma' lalu qiyas.

Terkait dengan masalah ijab kabul dengan lafal selain inkāh dan tazwijj, menurut Ibnu Taimiyah bahwasanya akad nikah dengan lafal kiyasan menurut adat kebiasaan dalam suatu akad pada hakikatnya lebih jelas dari lafal "Ankahtu",

53 Ibid, 16.

54 Muhammad Syaikhon, "Pemikiran Hukum Islam Ibnu Taimiyah," Ittihad 7, no. 2, (n.p: December 2015), 342. 
karena sesungguhnya lafal ini masih berkaitan antara al-Wathi' dan al-Akad.55 Adapun lafal "al-Imlāk (kepemilikan)" merupakan lafal khusus di dalam akad, maka akan langsung dapat difahami jika seseorang berkata: "Amlaktu Fulān 'Ala Fulānah (Aku kuasakan fulan atas fulanah)". Maka penetapan bolehnya memakai lafal selain inkāh dan tazwïj dalam akad nikah adalah sah, atas dasar hadits dari

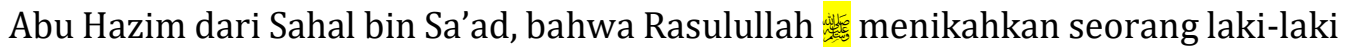
yang pada saat itu sahabat tersebut tidak mempunyai harta untuk dijadikan mahar, laku Rasulullah 能 mengucapkan:

$$
\text { ...... فقد ملكتكها بما معك من القرآن }
$$

“..Aku kuasakan wanita ini kepada mu dari al-Qur'an...(HR. Bukhari)"

Ibnu Taimiyah berpendapat, bahwasanya nikah adalah suatu penetapan dengan maksud dan tujuan nikah. adapun pernikahan merupakan salah satu bentuk ibadah yang mana membutuhkan dalil syar'i, kemudian akad dalam pernikahan sendiri adalah satu jenis ibadah yang tidak di syari'atkan dalam penetapan lafal. ${ }^{56}$

\section{Analisis Terhadap Pendapat dan Istinbāt Hukum Pemikiran Ibnu Taimiyah Tentang Ijab Kabul dengan Lafal Selain Inkāh dan Tazwïj}

Sebagaimana yang dijelaskan oleh Ibnu Taimiyah dalam kitab Majmū' Fatāwa jilid 32:

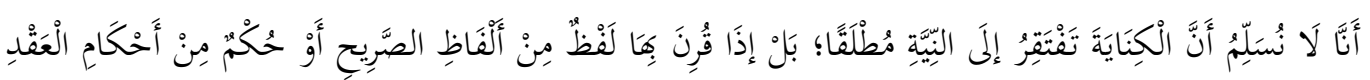

$$
\begin{aligned}
& \text { كَانَتْ صَرِيحَة. }
\end{aligned}
$$

Bahwasanya Ibnu Taimiyah tidak menganggap bahwa kiyasan itu tidak membutuhkan niat secara muthlak, akan tetapi jika kiyasan tersebut dihubungkan dengan lafal dari lafal-lafal yang jelas, atau dihubungkan dengan suatu hukum dari hukum-hukum akad, maka lafal kiyasan tersebut menjadi jelas.

Landasan hukum yang dipakai oleh Ibnu Taimiyah adalah as-Sunnah yaitu hadits yang diriwayatkan oleh Bukhari Muslim, sebagaimana yang dipaparkan dalam kitab Majmū' Fatāwa sebagai berikut:

$$
\text { كما فن الصحيحين:(ملكتكها على ما معك من القرآن) سواء كانت الرواية باللفظ أو بالمعنى (Akuhahalu }
$$

"Sebagaimana di dalam Shahihain bahwasanya Rasulullah Bersabda: (Aku telah menguasakan kamu kepadanya (anak perempuan) di atas apa yang menyertaimu dari al-Qur'an), sama saja, sekiranya riwayat itu dengan lafal atau makna." 32,15 .

55 Taqiyuddin Abu Abbas Ahmad bin Abdulhalim bin Taimiyah al-Huranii, Majmū' Fatāwa Juz 56 Ibid.

57 Ibid, 16. 
Ibnu Taimiyah berpendapat bahwa ijab kabul dalam akad nikah boleh menggunakan lafal selain inkāh dan tazwijj, apabila lafal tersebut menunjukkan maksud pernikahan, maka akad nikah seperti ini dianggap sah. Pendapat Ibnu Taimiyah tersebut, juga sependapat dengan Imam Malik.

Menurut peneliti bahwa ijab kabul yang diucapkan selain menggunakan lafal inkāh dan tazwīj, adalah perbuatan yang tidak dilarang, bahkan akad nikahnya dianggap sah, karena segala perbuatan yang kita lakukan adalah tergantung dengan apa yang dimaksudkan juga makna yang kita pahami, selama perbuatan tersebut tidak menentang pada syari'ah Islam. Sebagaimana kaidah fikih:

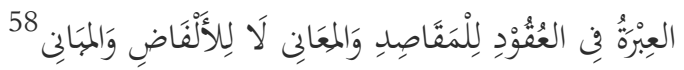

"Yang dijadikan pegangan dalam akad adalah maksud dan maknanya, bukan lafal dan susunan redaksinya.

Menurut analisis peneliti, metode istinbath yang digunakan Ibnu Taimiyah tentang masalah ijab kabul dengan lafal selain inkāh dan tazwij menggunakan metode Qiyas yang bersumber dari hadits Rasulullah 緿,

$$
\text { (.... فقد ملكتكها بما معك من القرآن.... }
$$

"Aku telah menguasakan kamu kepadanya dari hafalan yang kamu miliki" (HR. Bukhori).

Ibnu Taimiyah mengkiyaskan antara kalimat "Malaktukaha" dalam konteks hadits tersebut yang tidak memakai kalimat "Ankahtukaha", dengan lafal selain inkāh dan tazwij dalam ijab kabul seperti at-tamlīk, hibah, al-athiyah, juga lafal yang semisalnya. Metode ini adalah metode qiyas yang berlandaskan pada nash (al-Qur'an dan as-Sunnah) yang ada, serta tidak bertentangan dengan nash-nash yang lain.

Kesimpulan yang peneliti pahami dalam permasalahan ketentuan lafal ijab kabul dalam pernikahan, adalah jika lafal dalam ijab kabul tidak menggunakan lafal inkāh dan tazwīj sebagaimana apa yang telah dipaparkan oleh Ibnu Taimiyah, maka pernikahan keduanya sah, apabila lafal yang digunakan adalah lafal yang shārih (jelas) serta dapat difahami oleh para saksi nikah.

\section{Kesimpulan}

Menurut Ibnu Taimiyah bahwa ijab kabul dengan lafal selain inkāh dan tazwīj adalah sah akad nikahnya, jika lafal yang digunakan adalah lafal yang jelas dan dapat difahami oleh para saksi. Adapun jika lafal ijab kabul dihubungkan dengan lafal-lafal yang jelas, maka ijab kabulnya menjadi jelas dan tak perlu ada penjelasan lagi.

Metode istinbāt yang dipakai oleh Ibnu Taimiyah tentang bolehnya

${ }^{58}$ Abdul Karim Zaidan, Al-Wajiz, (Jakarta: Pustaka al-Kautsar, 2019), hal 14. 
mengucapkan ijab kabul dengan lafal selain inkāh dan tazwīj adalah dengan metode qiyas. Ibnu Taimiyah menyamakan bolehnya mengucapkan ijab kabul dengan selain inkāh dan tazwijj, sebagaimana sabda Rasulullah 能 ketika beliau menikahkan sahabatnya yang pada saat itu tidak memiliki harta sama sekali untuk di jadikan mahar, dengan menggunakan lafal "Amlaktukaha". 


\section{DAFTAR PUSTAKA}

Abidin, Slamet. Fikih Munakahat. 1st ed. Bandung: CV Pustaka Setia, 1999.

Al-Albani, Muhammad Nashiruddin et al. Shahih Fikih as-Sunnah Jilid 4. trans. Abu Ihsan al-Atsari. Jakarta: Pustaka at-Tazkia, 2008.

Al-Atsqalani, Ibnu Hajar. Fathul Bāri Syarah Shahih al-Bukhari Jilid 25. Trans. Amiruddin. Jakarta: Pustaka Azzam, 2008.

Al-Amidi, Saifuddin Abi Hasan Ali bin Muhammad. Al-Ahkam Fi Ushul al-Ahkam. Beirut: Dar al-Fikr, 1996.

Al-Asyrar, Umar Sulaiman. Pernikahan Syar'i. 1st ed. Solo: Tiga Serangkai, 2015.

Al-Azdii, Abu Dawud Sulaiman bin al-Asy'ats as-Sajastani. Sunan Abu Dawud Jilid 2. n.p.: Darul al-Fikri, n.d.

Al-Bukhari, Abu Abdillah Muhammad bin Ismail bin Ibrahim. Shahih Bukhari Jilid 5. Surabaya: Maktabah wa Mudhba'ah Thaha, 1981.

Al-Huranii, Taqiyuddin Abu Abbas Ahmad bin Abdulhalim bin Taimiyah. Majmū' Fatāwa Juz 32. al-Madinah al-Munawwarah: Mujamma' al-Malik Fahdin Lithabaathi al-Mushafi asy-Syarif, 1995.

Al-Jamal, Hasan. Biografi 10 Imam Besar. 1st ed. Jakata: Pustaka Al-Kautsar, 2005.

Al-Juzairi, Abdurrahman. Fikih Empat Madzhab. 6th ed. Vol. 5. Jakarta: Pustaka AlKautsar, 2012.

As-Saraji, Muhammad 'Ali. al-Lubāb Fi Qawā'id al-Lughah Jilid 1. Damaskus: Dar alFikr. Maktabah Syamilah

Ar-Rifa', Muhammad Nasib. Taysiru Al-Aliyyul Qadir Li Ikhtisari Tafsir Ibnu Katsir. Trans. Syihabuddin. Jakarta: Gema Insani, 2004.

Ayyub, Hasan. Fikih Keluarga. 5th ed. Jakarta Timur: Pustaka Al-Kautsar, 2006.

Azhim, Said Abdul. Ibnu Taimiyah Pembaruan Salafi Dan Dakwah Reformasi. 1st ed. Jakarta: Pustaka Al-Kautsar, 2005.

Farid, Ahmad. Biografi 60 Ulama Ahlus Sunnah. 4th ed. Jakarta: Darul Haq, 2016.

Haroen, Nasrun. Ushul Fiqih. Jakarta: Logos Publising, 1996.

Islam, Dewan Redaksi Ensiklopedi. Ensiklopedi Islam. 11th ed. Vol. 5. Jakarta: Ichtiar Baru Van Hoeve, 2003.

Khallaf, Abdul Wahab. Ilmu Ushul Fiqih. Jakarta: Al-Majlis al-'A'la Indonesia Li adDakwah, 1972.

Mathlub, Abdul Majid Mahmud. Panduan Hukum Keluarga Sakinah. Solo: Era Intermedia, 2005. 
Munawwir, Achmad Warson. Kamus al-Munawwir Arab-Indonesia. Jakarta: Pustaka Progressif, 1997.

Sabiq, Sayyid. Fiqih Sunnah. 1st ed. Vol. 2. Jakarta Timur: Al-I'tishom, 2010.

Sarwat, Ahmad. Seri Fiqih Kehidupan. Vol. 8. Jakarta: Rumah Fiqih Publishing, 2017.

Syaikh, Abdullah bin Muhammad dan Abdurrahman bin Ishaq Alu. Lubābut Tafsir Min Ibni Katsir Jilid 6. Trans. Abdul Ghoffar dan Abu Ihsan al-Atsari. Bogor: Pustaka Imam Syafi'i, 2008.

Zaidan, Abdul Karim. Al-Wajiz. Jakarta: Pustaka al-Kautsar, 2019.

\section{Sumber Referensi Website}

"Pengertian Kinayah dan Macam-Macamnya” Hahuwa. accessed September. 2017. https://hahuwa.blogspot.com/.

\section{Sumber Referensi Jurnal}

Syaikhon, Muhammad. "Pemikiran Hukum Islam Ibnu Taimiyah" ittihad 7, no. 2. (December 2015).

Yasin, Achmad. Ilmu Ushul Fiqih (Dasar-Dasar Istinbat Hukum Islam). Prodi Siyasah Jinayah Jurusan Hukum Islam. Fakultas Syari'ah dan Hukum UIN Sunan Ampel Surabaya, 2007.

Wibisana Wahyu. "Pernikahan dalam Islam”. Ittihad 14, no. 2. ( n.p, 2016).

Qamaruzzaman, Pemikiran Politik Ibnu Taimiyah, STAI Mempawah Kalimantan Barat, ittihad 2, no, 2 (Desember 2019) 